\title{
SISTEM KENDALI JARAK JAUH BERBASIS WEB UNTUK SISTEM RUMAH PINTAR
}

\author{
Mumuh Muharam*, Melda Latif, dan Mahendri Saputra \\ Jurusan Teknik Elektro, Fakultas Teknik, Universitas Andalas \\ *Corresponding author, e-mail: mumuh@eng.unand.ac.id
}

\begin{abstract}
Abstrak - Pengendalian piranti elekronika yang masih menggunakan cara konvensional yaitu dengan menyalakan dan mematikannya melalui saklar manual, akan membatasi upaya masyarakat untuk melakukan penghematan energi listrik. Karena itu penggunaan system kendali yang terintegrasi dalam bentuk rumah pintar (smart home) akan membuat upaya penghematan energi lebih mudah dilakukan. Tujuan makalah ini adalah untuk membuat sebuah sistem yang menerapkan konsep Internet of Things (IoT) dan sistem kendali jaringan (NCS) untuk aplikasi rumah pintar, dengan mengimplementasikan sebuah perangkat komputer berukuran kecil bernama Raspberry Pi yang digunakan sebagai server dan pengendali kerja sistem. Prinsip kerja dari sistem ini adalah pengendalian piranti elektronika dari jarak jauh pada sebuah bangunan melalui website lokal yang diakses menggunakan jaringan internet lokal melalui Smart phone. Dari hasil pengujian, sistem yang dibangun mampu mengendalikan tujuh peralatan bertegangan AC dan tiga alat elektronik tegangan DC sekaligus dan mampu menampilkan status masing-masing piranti elektronika yang dikendalikan.
\end{abstract}

\section{Kata Kunci : Internet of Things (IoT), Rumah Pintar, Sistem Kendali Jaringan, Raspberry Pi.}

\begin{abstract}
Conventional control of electronic devices that still use manual on and off switches will limit the ability of public to achieve energy saving. Therefore, application of automatic controller in form of smart home will make energy saving effort will easier to achieve. This paper aims to design a system with concept of Internet of Things (IoT) for smart home application, by implementing a small computer device named Raspberry Pi which is used as server and control system. The principle of this system is to control electronic devices in a building through a local website using local internet network via a smart phone. The test results show that the system is able to control seven AC equipment and three DC voltage electronical devices in simultaneously. The system also able to display the status of each controlled electronics devices.
\end{abstract}

Keywords : Internet of Things (IoT), Smart Home, Networked Control System (NCS), Raspberry Pi.

\section{Pendahuluan}

Terdapat dua hal yang memberikan kerugian dalam konsep rumah konvensional. Pertama, pengabaian terhadap perangkat kelistrikan seperti lampu-lampu penerangan atau perangkat lainnya lupa untuk dimatikan pada saat ke luar rumah sehingga pemakaian energi menjadi boros. Kedua, kurangnya penjagaan terhadap keamanan rumah misalnya pintu atau garasi lupa dikunci sehingga dapat menimbulkan tindakan kejahatan. Rumah pintar [1] memberikan solusi yang dapat diterapkan terhadap hal tersebut. Bahkan rumah pintar dapat memberikan kenyamanan dari segi pengkondisian ruangan seperti ventilasi dan pengaturan suhu ruangan dan memiliki keamanan baik dari segi kecerobohan terhadap pengabaian perangkat kelistrikan ataupun dari segi tindak kejahatan secara otomatis. Untuk rumah pintar kriteria yang optimal agar dapat direalisasikan harus memiliki kemampuan dijangkau atau dikendalikan pada jarak jauh. Salah satu media pengendalaian jarak jauh adalah dengan memanfaatkan internet.

Dua konsep yang dapat digunakan untuk merealisasikan rumah pintar yaitu Internet of Things (IoT) dan Sistem Kendali Jaringan (Networked Control Systems-NCS). IoT memberikan fasilitas terhadap semua perangkat elektronik agar dapat terkoneksi dan terintegrasi dalam sebuah jaringan [2-3], sementara NCS memberikan sistem kendali terhadap perangkatperangkat elektronik tersebut dengan memperhatikan tanggapan waktu apabila internet terdapat kendala seperti packet-dropout dan kehadiran waktu tunda [4-5].

Tujuan penelitian ini adalah untuk 
membangun sebuah sistem yang mengendalikan rumah pintar dari jarak jauh dengan memanfaatkan media internet. Dari sisi IoT, sistem yang dibangun untuk memonitor lampulampu ruang dan kipas angin, sedangkan dari sisi NCS motor servo digunakan untuk sistem pengendalian jarak jauh. Sistem yang dibangun menggunakan Raspberry Pi sebagai pengendali dan komunikasi perangkat keras dan perangkat lunak.

\section{Tinjauan Pustaka}

\subsection{Rumah Pintar}

Dewasa ini konsep rumah pintar dalam [1] telah berkembang dengan pesat. Perkembangan perangkat IC, elektronika dan komunikasi dan seperti juga perangkat lunak telah memberikan sumbangan yang sangat penting untuk model rumah pintar, terutama rumah pintar yang dapat dikendali dari jarak jauh. Penelitian rumah pintar tidak hanya rumah sebagai objek penelitian tetapi telah berkembang ke model yang lebih besar dan komplek seperti gedung pintar, rumah sakit pintar, dan kota pintar [6].

Penelitian rumah pintar berkembang dari pengendali yang bersifat lokal seperti Bluetooth [7], RFID [8], Wi-fi [9] ke arah pengendali yang mencakup daerah jangkauan yang lebih luas menggunakan model berbasis Web [10].

\subsection{Internet of Things (IoT)}

IoT memungkinkan interaksi antara mesin yang satu dengan mesin lainnya (M2M, machine to machine) seperti peralatan elektronik rumah tangga, sensor dan actuator, dan HP/computer. IoT dapat bekerja dengan baik memerlukan tiga hal berikut yaitu pemahaman bersama terhadap pengguna dan aplikasinya, arsitektur softwarwe dan jaringan komunikasi untuk memproses dan menyalurkan informasi, dan perangkat analisis yang bertujuan untuk keperluan otomatisasi dan kemampuan cerdas [3].

\subsection{Sistem Kendali Jaringan (NCS)}

NCS merupakan sistem kendali dimana sinyalsinyal kendali dan umpan-balik melalui media internet [4]. Pada dasarnya NCS hampir sama dengan IoT, hanya saja pada NCS analisis mengenai tanggapan sistem agar sistem tetap stabil dan unjuk kerja juga tetap baik. Oleh karena internet memiliki banyak kendala seperti packetdropout atau waktu-tunda, maka sistem akan sangat terpengaruh unjuk kerjanya atau menjadi tidak stabil [11].

\section{Metodologi}

\subsection{Rancangan Arsitektur Rumah Pintar}

Rumah pintar yang dirancang terdiri dari dua bagian yaitu perangkat keras dan perangkat lunak. Perangkat keras terdiri dari Raspberry Pi, relai, dan perangkat elektronik yang akan dikendalikan seperti lampu, kipas, dan motor servo kontinyu. Sementara, perangkat lunak digunakan mengendalikan semua sistem.

Tinjau Gambar 1 yang memperlihatkan arsitektur Rumah pintar yang dirancang. Terlihat bahwa terdapat tiga bagian yaitu akses dari klien, Raspberry Pi sebagai pusat pengendali, dan perangkat elektronik yang dikendalikan.

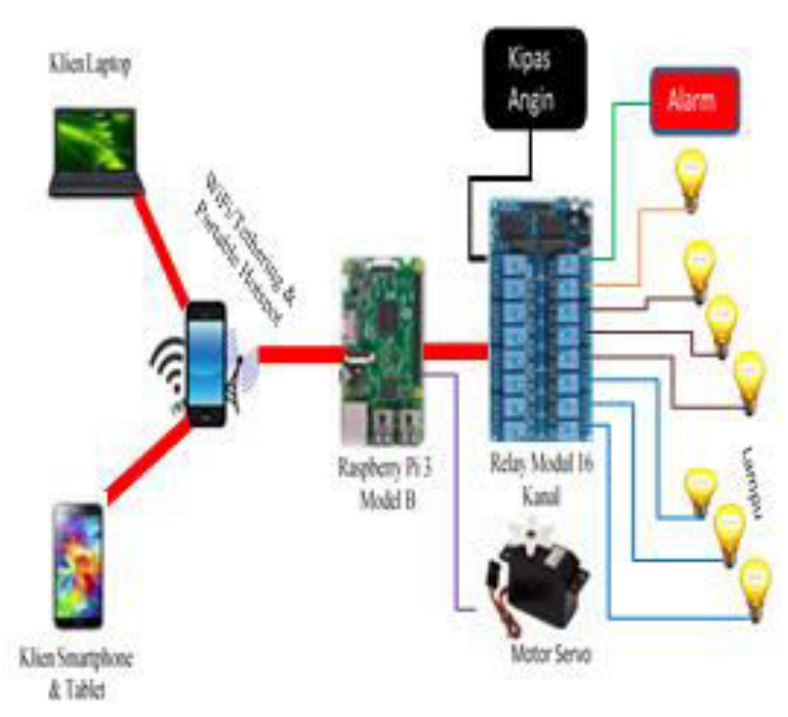

Gambar 1. Arsitektur Rumah Pintar

\subsection{Akses Klien}

Akses dari klien dirancang sebagai berikut pertama yang harus dilakukan adalah mengkonfigurasi IP address smartphone, laptop atau perangkat sejenis sesuai dengan jaringan lokal. Setelah IP address client terkonfigurasi sambungkan perangkat client dengan jaringan internet. Jika tidak bisa tersambung dengan jaringan internet lokal, kemungkinan terjadi kesalahan pada pengkonfigurasian IP address, ulangi langkah pengkonfigurasiannya. setelah tersambung ke jaringan lokal, buka web browser, kemudian buka halaman web sistem kendali listrik jarak jauh. Pada halaman web sistem kendali listrik hanya dibatasi pada status relay 
melalui button, fungsi relay on dan off untuk lampu, kipas angin, alarm, serta buka dan tutup garasi menggunakan motor servo.

\subsection{Raspberry Pi dan Perangkat Kendalian}

Tinjau Gambar 2 yang merupakan diagram rangkaian hardware sistem yang menjelaskan bahwa Raspberry Pi 3 Model B sebagai main sistem karena sebagai kontrol utama sistem dan sebagai server yang disuplai dengan adaptor minimal 5V 1A. Sedangkan pin GPIO pada Raspberry $\mathrm{Pi}$ berfungsi sebagai rangkaian pengendali output.

Wiring diagram rangkaian hardware sistem diatas menunjukkan sistem mengontrol 10 alat elektronika yang terdiri dari 7 buah lampu pijar, 1 buah kipas angin, 1 buah buzzer melalui 9 buah relay dan 1 buah motor servo yang dihubungkan langsung ke pin GPIO.

Tegangan 3.3V DC dari GPIO digunakan sebagai tegangan trigger untuk relay yang di ground kan yang berasal dari pin VCC Raspberry Pi. Kemudian tegangan 12V DC digunakan untuk men-driver masing-masing relay yang di-groundkan yang berasal dari power supply. Sedangkan tegangan 5V DC digunakan untuk menyuplai motor servo yang di ground kan yang berasal dari power supply.

Pin GPIO 23, 24, 25, 12, 16, 19, 20, 21, 26 merupakan rangkaian pengendali output sistem yang akan mengeluarkan output berupa logika low atau 0 dan logika high atau 1. Jika keluaran pin GPIO berupa logika low atau 0 maka tegangan $3.3 \mathrm{~V}$ dari pin VCC Raspberry Pi akan mentrigger kumparan relay, menyebabkan tercipta medan elektromagnetik yang menarik kontak poin relay menjadikan relay aktif sehingga sehingga lampu, buzzer dan fan/kipas angin berukuran kecil menyala.

Jika output program berupa logika high atau 1 maka arus 3.3V dari pin VCC Raspberry Pi akan terputus, sehingga tidak ada arus di kumparan relay, maka kemagnetan relay hilang dan kontak poin relay akan terpisah menjadikan relay tidak aktif sehingga lampu, buzzer dan fan/kipas angin berukuran kecil alan mati. Hal ini terjadi karena relay yang digunakan bertipe aktif low. Selain mengeluarkan output berupa low dan high, pin GPIO juga mengeluarkan output berupa sinyal PWM yakni pin GPIO 18 dengan DutyCycle $>1.5$ $\mathrm{ms}$ dan $<1.5 \mathrm{~ms} 18$ untuk mengatur rotasi motor servo dengan ketentuan jika output berupa DutyCycle > $1.5 \mathrm{~ms}$ maka motor servo akan berotasi searah jarum jam. Sebaliknya jika output berupa DutyCycle $<1.5 \mathrm{~ms}$ maka motor servo akan berotasi berlawanan jarum jam.

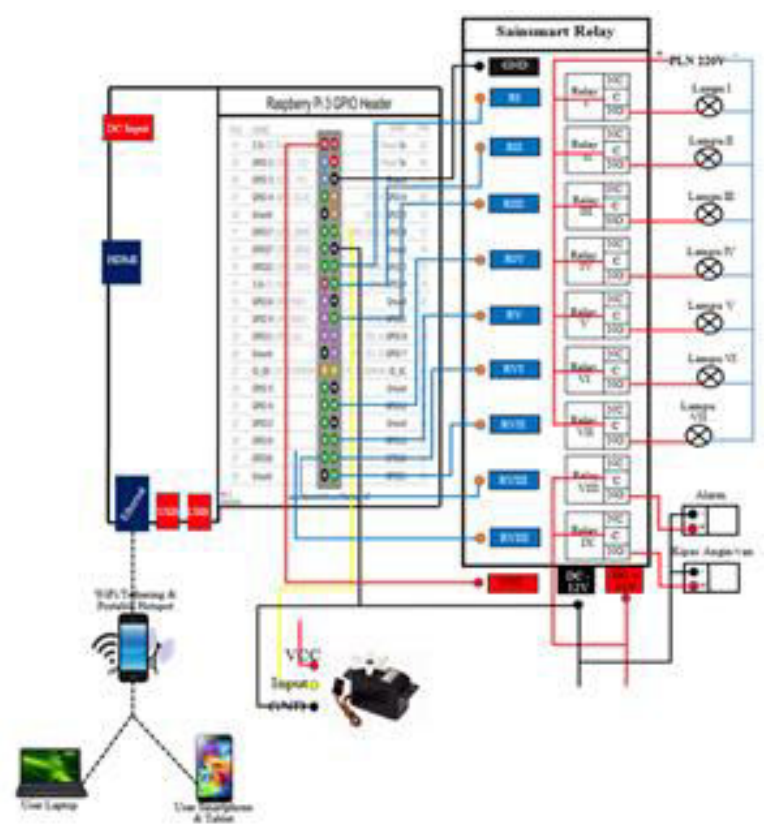

Gambar 2. Diagram Rangkaian Input-output Rapsberry PI

\subsection{Perancangan Perangkaat Lunak}

Pada sistem kendali jarak jauh ini pemrograman untuk mengendalikan perangkat elektronik menggunakan bahasa Python. Beberapa program yang dirancang adalah sebagai berikut:
a. Program on/off tujuh buah lampu
b. Program on//off kipas angin kecil
c. Program pemutaran motor servo
d. Program untuk alarm

Selain pemprograman Bahasa Python, dalam rancangan rumah pintar ini juga dilakukan pemprograman untuk keseluruhan sistem menggunakan bahasa program HTML dan PHP yaitu sebagai berikut:
a. Program statement kondisi
b. Program status relay
c. Program tampilan dan kondisi button

\subsection{Metode Pengujian}

Pengujian yang dilakukan meliputi:

a. Penyalaan lampu dan mematikan lampu, kipas angin

b. Pengendalian motor servo

c. Pemberian gangguan pada pengendalian 
motor servo

\section{Hasil dan Pembahasan}

Hasil pengujian dan pembahasan sangat diperlukan untuk menilai kinerja sistem kendali jarak jauh ini apakah memiliki unjuk kerja yang baik dan untuk mendapatkan kelemahan sistem untuk penelitian lebih lanjut.

\subsection{Hasil Perancangan Web Browser}

Gambar 3 memperlihatkan tampilan hasil perancangan sistem kendali jarak jauh berbasis Web pada Smart Phone. Terlihat bahwa sistem dibentuk dalam tiga bagian. Bagian pertama berupa pengendali lampu, pengendali kipas, dan motor Bagian kedua adalah alarm. Sedangkan bagian ketiga merupakan penjadwalan penyalaan lampu.

Aksi yang dilakukan berupa penekan tombol pada ketiga bagian pengendali tersebut. Hasil dari penekanan tombol aksi terlihat pada status. Selanjutnya tampilan perangkat kerasnya terlihat pada Gambar 4. Lampu akan menyala apabila tombol lampu ditekan.

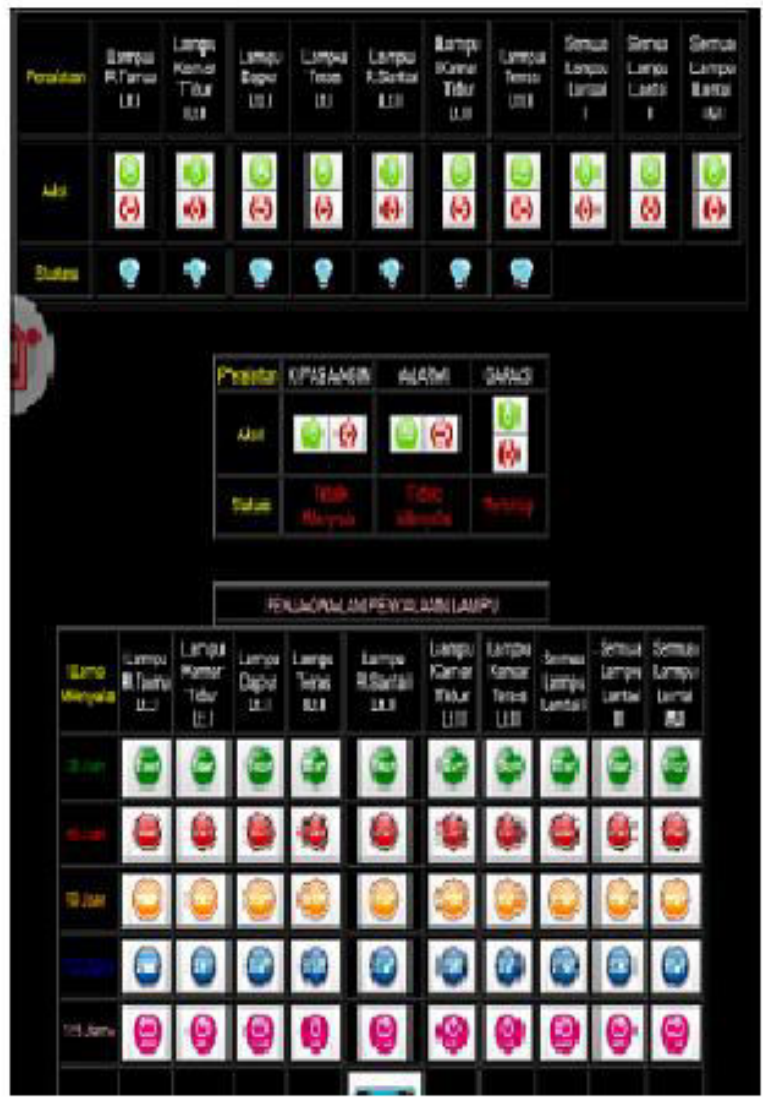

Gambar 3. Tampilan Web Sistem Kendali Pada Smart Phone

\subsection{Kendali Lampu}

Pengujian lampu dilakukan baik untuk setiap lampu ataupun untuk satu array yaitu lampulampu pada setiap lantai. Selain hal tersebut, pengujian juga dilakukan untuk lampu yang dikendalikan penyalaannya sesuai jadwal. Hasil memperlihatkan bahwa pengendalian berjalan dengan baik.

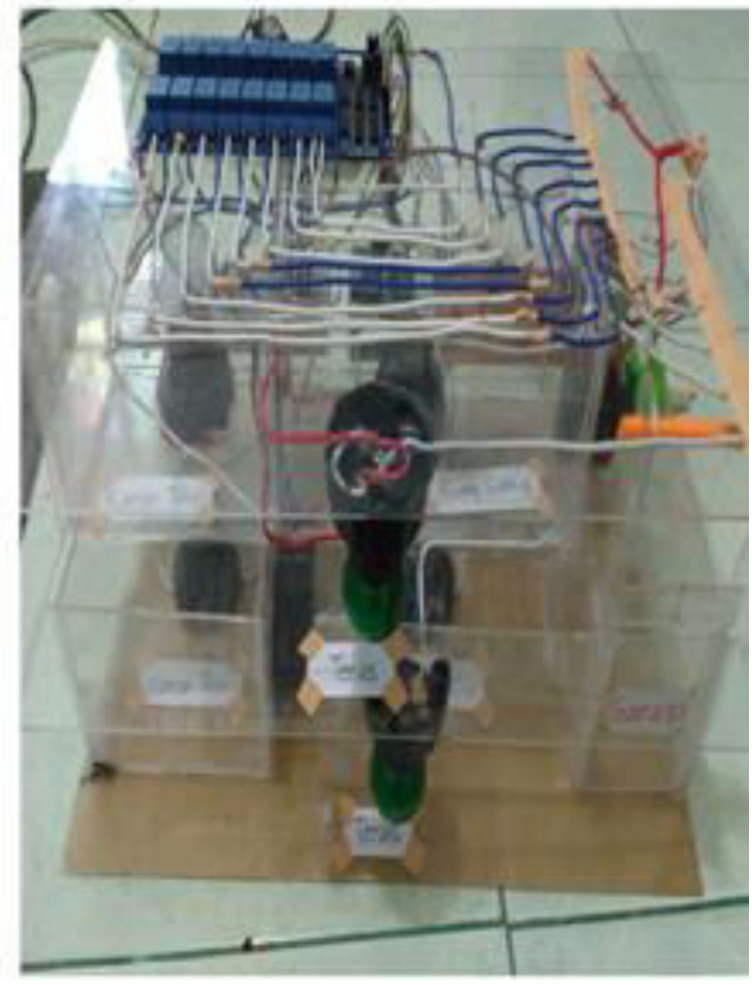

Gambar 4. Model Rumah Pintar

\subsection{Kendali Motor Servo}

Motor servo diterapkan pada beban pintu garasi. Aksi yang dilakukan adalah membuka atau menutup garasi. Hasil memperlihatkan bahwa pengendalian motor servo ini dapat berjalan sesuai rancangan.

\subsection{Kendali Motor Servo Dengan Gangguan}

Pada pengujian ini motor servo dijalankan dengan memberikan gangguan berupa pembebanan pada internet. Hasil pengujian terlihat pada Tabel 1. Terlihat bahwa waktu respon motor servo terjadi perubahan yang sangat kecil meskipun gangguan diperbesar. Hal ini memperlihatkan bahwa sistem kendali jarak jauh yang berbasis $W e b$ ini masih kokoh. 


\subsection{Alarm}

Salah satu aspek dalam sistem rumah pintar adalah keamanan. Untuk memperlihatkan bahwa keamanan pun dapat dikendalikan sebuah buzzer dipasang pada pintu. Apabila terjadi kejanggalan pada pintu maka alarm akan menyala. Alarm yang digunakan pada penelitian ini pun dapat bekerja sesuai pengguna yaitu dengan menekan tombol aksi pada halaman $W e b$, sehingga sewaktu-waktu dapat bekerja.

Tabel 1. Respon Motor servo terhadap pembebanan internet

\begin{tabular}{|ccc|}
\hline No & $\begin{array}{c}\text { Jumlah Halaman Web } \\
\text { Yang Diakses }\end{array}$ & $\begin{array}{c}\text { Waktu } \\
\text { Respon } \\
\text { (Detik) }\end{array}$ \\
\hline 1 & 3 & 0.45 \\
\hline 2 & 5 & 0.45 \\
\hline 3 & 7 & 0.46 \\
\hline 4 & 9 & 0.46 \\
\hline 5 & 11 & 0.47 \\
\hline
\end{tabular}

\subsection{Pembahasan}

Secara umum hasil penelitian memperlihatkan bahwa pengendalian jarak jauh menggunakan internet dapat diterapkan dengan baik. Unjuk kerja dan kestabilan sistem kendali tetap baik walaupun sistem diberikan pembebanan.

Jumlah perangkat elektronik yang diteliti sangat banyak dan macam-macam perangkat juga bervariasi tidak membuat Raspberry Pi dan sistem menjadi tidak stabil. Terlihat dari percobaan bahwa ketika aksi dilakukan untuk semua perangkat sistem masih dapat menanggapi dengan baik. Sebagai contoh semua lampu dinyalakan baik di lantai 1 dan 2 ataupun dengan aksi pada kipas angin sistem dapat bekerja.

\section{Kesimpulan}

Dalam paper ini telah disajikan sistem kendali jarak jauh berbasiskan web. Sistem menggunakan Raspberry Pi yang merupakan perangkat berdimensi kecil tetapi dapat melakukan proses kendali, komunikasi, dan menanggapi semua komponen sistem.

Hasil percobanan memperlihatkan apabila dilihat dari jumlah dan variasi perangkat maka sistem tetap stabil dan berunjuk kerja baik. Begitu pula pada saat diberikan pembebanan pada jaringan internet, sistem tetap stabil dan berunjuk kerja baik.

Untuk penelitian lanjut, penambahan perangkat elektronik seperti sensor atau aktuator dapat meningkatkan fungsi dari rumah pintar. Sebagai contoh penambahan sensor pendeteksi dini kebakaran untuk meningkatkan keamanan rumah atau pendeteksi maling untuk mencegah kejahatan.

Pada penelitian ini, Pengguna masih bersifat pengguna tunggal. Penelitian lanjut dapat ditinggkatkan menjadi banyak pengguna seperti pada penelitian [12], dimana konsep IoT yang digunakan adalah IoT tersebar.

\section{Ucapan Terima Kasih (Acknowledgement)}

Ucapan terima kasih penulis tujukan kepada Fakultas Teknik Universitas Andalas yang telah memberikan dukungan dana penelitian dalan kontrak perjanjian No, 099/UN.16.09.D/PL/2017.

\section{Daftar Pustaka}

[1] Harper, Richard, ed. Inside the smart home. Springer Science \& Business Media, 2006.Atzori, L., Iera, A., and Morabito, G., The Internet of Things: A survey, Computer Networks 54, 2787-2805, 2010.

[2] Gubbi, J., Buyya, R., Marusic, S. and Palaniswami, M., Internet of Things (IoT): A vision, architectural elements, and future directions, Future Generation Computer Systems 29, 1645-1660, 2013.

[3] Gupta, R.A. \& Chow, M.Y., Networked Control Systems: Overview and Research Trends, IEEE Trans. on Industrial Electronics, 57(7), pp. 2527-2535 July, 2010.

[4] Najmurrokhman, A., Riyanto, B., Rohman, A.S., dan Hendrawan, Dissipative Controller Design for Networked Control Systems via the Markovian Jump System Approach, J. Eng. Technol. Sci., Vol. 45, No. 1, 25-46, 2013.

[5] Shi, Y. \& Yu, B., Output Feedback Stabilization of Networked Control Systems with Random Delays Modeled by Markov Chains, IEEE Trans. on Automatic Control, 54(7), pp. 1668-1674 July, 2009.

[6] Kortuem, G., Kawsar, F., Fitton, D. and Sundramoorthy, V., Smart objects as building blocks for the internet of things, Internet Computing, IEEE, vol. 14, 44-51, 2010. 
[7] Alkar, A., and Buhur, U., An Internet based wireless home automation system for multifunctional devices, IEEE Trans. on Consumer Electronics 51, 1169-1174, 2005.

[8] Sharma, U. and Reddy S. R. N., Design of Home/Office Automation Using Wireless Sensor Network, International Journal of Computer Applications, vol. 43, 53-60, 2012.

[9] Lianjin, G. and Guosheng, W., Design for Indoor Environment Monitoring System based on Embedded System and Multisensor Data Fusion Algorithm, International Journal of Smart Home. Vol. 10, No. 1, 31-40, 2016.

[10] Seiler, P. and Sengupta, R., An $H_{\infty}$ Approach to Networked Control, IEEE Trans. On Automatic Control 50 (3), 356364 March, 2005.

[11] Roman, R., Zhou, J., and Lopez, J., On the features and challenges of security and privacy in distributed internet of things, Computer Networks 57, 2266-2279, 2013.

\section{Biodata Penulis}

Mumuh Muharam menjalani pendidikan S1 di jurussan Teknik Fisika ITB dan lulus pada tahun
1993, sedangkan pendidika S2 pada Program Pasca sarjan Teknik Elektro dan lulus 2000. Sejak tahun 1998 sampai sekarang bekerja sebagai Dosen di jurusan Teknik Elektro Fakultas Teknik Unand. Adapun bidang penelitian yang ditekuni adalah penelitian di bidang Teknik kendali baik yang bersifat teoritis ataupun aplikasi berbasiskan teknologi komputer atau internet.

Melda Latif menamatkan pendidikan S1 di bidang Teknik elektro pada Universitas Sumatra Utara (USU) pada 1994 dan lulus pada jenjang pendidikan S2 di program Pascasarjana Teknik Elektro pada 2006. Sejak tahun 1998 sampai sekarang bekerja sebagai Dosen di jurusan Teknik Elektro Fakultas Teknik Unand. Adapun bidang penelitian yang ditekuni adalah penelitian di bidang konversi energi seperti penelitian pada energi terbarukan dan penelitian yang berkaitan dengan teknologi pengendalian mwsin-mesin listrik.

Mahendri Saputra menjalani pendidikan S1 di jurusan Teknik Elektro Fakultas Tekni Unand dan lulus pada 2017. Penelitian yang ditekuni adalah pengendalian dan penerapan teknologi yang berbasiskan internet. 